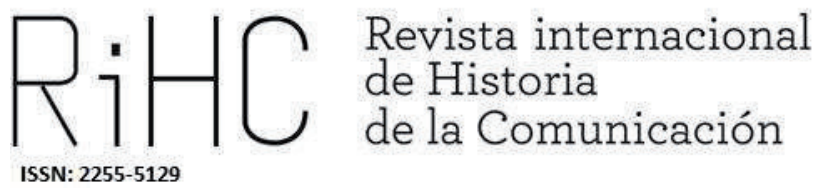

\title{
CONOZCA USTED ESPAÑA O SU NUEVA IMAGEN: CONTEXTO Y RECEPCIÓN DE UNA CAMPAÑA TELEVISIVA PARA EL BOOM TURÍSTICO INTERNO ${ }^{1}$
}

\section{Get to know Spain or its new image: context and reception of a TV campaign for the domestic tourist boom}

DOI: http://dx.doi.org/10.12795/RiCH.2021.i16.19

Recibido: 15-3-2021

Aceptado: 3-6-2021

Publicado: $30-6-2021$

Lucía Rodríguez García de Herreros

Universidad Carlos III de Madrid, España

lucrodri@hum.uc3m.es

ORCID (D) : 0000-0001-7686-484X

\footnotetext{
${ }^{1}$ Este artículo se ha realizado con apoyo del proyecto "Cine y televisión en la era del cambio digital y la globalización (1993-2008): identidades, consumo y formas de producción", financiado por la Agencia Estatal de Investigación (referencia PID2019-106459GB-100).
} 
Resumen: Los documentales ocuparon un lugar destacado en el crecimiento de la producción propia de TVE en los años sesenta. Conozca usted España fue una serie de referencia en este terreno, en la que divulgación y fascinación turística se dieron la mano en torno al ideario del entonces ministro de Información y Turismo, Manuel Fraga Iribarne. Se argumentará que las novedades que introdujo el programa en el medio televisivo deben leerse en el contexto de una red de medios, caracterizada por determinadas prácticas y ciertas preferencias ideológicas, cuyos objetivos eran renovar la imagen del país apelando a su diversidad y animar a los españoles a viajar.

Palabras clave: Historia de la televisión, TVE, Ministerio de Información y Turismo, turismo interno.

\begin{abstract}
Documentaries took a prominent place in the growth of TVE's ownproduction content in the 1960s. Conozca usted España was a reference series in this field, in which popularization and tourist fascination went hand in hand around the ideas of the then Minister of Information and Tourism, Manuel Fraga Iribarne. It will be argued that the news this program introduced in the medium should be read in the context of a media network, characterized by certain practices and ideological preferences. The aims were to renew the image of the country by appealing to its diversity and to encourage Spaniards to travel.
\end{abstract}

Keywords: TV history, TVE, Ministry of Information and Tourism, domestic tourism.

\title{
Introducción y metodología
}

El eslogan "Spain is different" ocupa un lugar preeminente en el imaginario colectivo dentro y fuera de las fronteras españolas; su amplio recorrido histórico no impide que el lema se asocie especialmente al boom turístico de los años sesenta. Su pervivencia ha eclipsado a otra frase que articuló numerosas iniciativas de promoción turística de ese mismo periodo: "Conozca usted España".

Utilizado sobre todo para el fomento del turismo interno, el Ministerio de Información y Turismo (en adelante, MIT) puso el lema a circular con subvenciones al turismo social, publicaciones y, en especial, una serie de televisión homónima ${ }^{2}$, emitida en TVE entre 1966 y 1969. Dicho programa, coordinado por Salvador Pons, se inspiró en las directrices del entonces ministro Manuel Fraga Iribarne y marcó las pautas de un nuevo modelo de documental para televisión en un momento clave: el despegue de la segunda cadena, la consolidación de la red de TVE y el crecimiento exponencial del número de televisores en España.

\footnotetext{
2 Para las referencias al conjunto de la campaña de promoción, se escribirá "Conozca usted España"; para la serie de televisión, Conozca usted España.
} 
Este artículo busca analizar las tensiones discursivas presentes en esa serie (localizables en su producción y recepción en prensa), en relación al delicado proceso de renovación de la imagen del país que el régimen aceleró en los sesenta. Se parte de la idea de que, por su temática, su ubicación en la historia de TVE y su contexto político, el programa puede ser un testimonio relevante para entender cómo el MIT fomentó entre los españoles el discurso turístico y desarrollista y cómo se recibió ese discurso.

Se propone que el análisis de la serie requiere una aproximación que no se cierre en torno a la historia de la televisión, sino que reconstruya la red de medios (en un sentido similar a la idea de Medienverbund, de Thomas Elsaesser) en que circuló. En el marco de esa red, según nuestra hipótesis, tuvo lugar un proceso de negociación que incorporó los intereses del MIT, las preferencias de los visitantes extranjeros, y las aspiraciones de la audiencia española. Vinculamos nuestro estudio a los análisis de los usos de la no ficción audiovisual, así como de los trasvases transmediáticos ${ }^{3}$ de significados.

El principal anclaje teórico en el que vamos a encuadrar nuestro estudio es, por tanto, el concepto Medienverbund, acuñado por Thomas Elsaesser y utilizado, por ejemplo, en su aportación respecto al análisis de la no ficción, ámbito al que también lo aplica Patrick Vonderau (2009: 163). El término puede definirse como "a network of competing, but also mutually interdependent and complementary media or media practices, focused on a specific location, a professional association, or even a national or state initiative" ${ }^{4}$ (Elsaesser, 2009: 22). Según el autor alemán, explicar esas interconexiones es clave a la hora de buscar los motivos para la producción de un documental, sus mecanismos de financiación y sus usos, tres aspectos que marcan singularmente el estudio de la no ficción.

Antes de entrar a analizar el programa Conozca usted España como parte de la campaña del mismo nombre, hay que realizar algunas puntualizaciones acerca de los trabajos que han estudiado la televisión en España en los años sesenta y primeros setenta. Estos han entendido su objeto de estudio de dos formas complementarias. En primer lugar, como un periodo clave de la historia del medio; en segundo, como uno de los símbolos del imaginario de esa etapa del franquismo denominada desarrollismo.

\footnotetext{
3 El término "transmedia" se ha desarrollado fundamentalmente al hilo de los nuevos entornos digitales; véase, por ejemplo, la influyente obra de Jenkins (2008). Sin embargo, hacemos nuestra la afirmación de Rueda Laffond de que también "es útil en la reflexión historiográfica para estudiar la circulación de contenidos multimediáticos poniendo el acento en fenómenos como las interrelaciones, los préstamos y las hibridaciones" (Rueda Laffond, 2018: 104).

4 “Una red de medios o prácticas mediáticas en competencia, pero también mutuamente dependientes y complementarios, centrados en una localización, una asociación profesional o incluso una iniciativa estatal" (nuestra traducción).
} 
En el primer sentido, el estudio de ese periodo ha sido una parte fundamental de las historias de la televisión española con vocación de abarcar periodos amplios, como las de Bustamante (2013) o la de Palacio (2008).

Recientemente han proliferado los estudios televisivos vinculados al análisis de programas, de géneros $y$, muy especialmente, a la programación. Valgan como ejemplos las aportaciones sobre ficción seriada de Canós y Martínez (2016), sobre programación de cine en la "primavera del aperturismo" de Zahedi (2014), o el estudio de la parrilla realizado por Antona (2016). Hay que recordar que la investigación de la recepción para este periodo se topa con ciertas dificultades metodológicas relacionadas con la falta de datos para programas concretos: como señalan Martín Quevedo y Fernández Ramírez (2020: 9), desde finales de los sesenta se realizaron encuestas que trataban de medir las audiencias o la aprobación de espacios de televisión, pero eran esporádicas, dispersas o incompletas en cuanto a las cifras de espectadores.

En el segundo sentido, numerosos autores han coincidido en la importancia de la televisión como símbolo de la cultura del desarrollismo. Sánchez-Biosca (2007) considera a la televisión un icono y elemento central para la cohesión social en el periodo. En su estudio de la imagen de la televisión en el cine de los sesenta, Camporesi (1999) analiza cómo las descripciones del medio pasaron de una indefinición casi reverencial, a una diversificación de las miradas.

Algunos análisis recientes que atienden por igual a estas dos vertientes (la televisión como medio y la televisión como icono) ponen sobre la mesa dos ideas fundamentales para entender la TVE de los sesenta en su contexto histórico.

Por una parte, subyace en muchas investigaciones sobre televisión la pregunta de hasta qué punto TVE era una herramienta de propaganda del régimen, o más bien un medio centrado en el entretenimiento, en el que incluso se colaban contenidos precursores de los cambios por venir. Rueda Laffond (2014) propone cierta síntesis entre ambas hipótesis basándose en el concepto desarrollado por Michael Billing, nacionalismo banal. Por nacionalismo banal entendemos un marco de interpretación ligado a lo cotidiano que funciona a modo de propaganda de baja intensidad para garantizar la hegemonía de algunas visiones; para nuestros propósitos, el caso más interesante de los señalados por Rueda Laffond es cómo TVE incidió en el último franquismo en una imagen de España unida pero diversa.

Por otra parte, Ibáñez (2017: 56) señala el componente aspiracional y la apelación a la modernidad en muchos de los discursos sobre la televisión, que se convertirá en escuela de comunicación para las nuevas generaciones de políticos. Es interesante que las observaciones de Ibáñez se realicen en el marco de un texto dedicado tanto al cine como a la televisión en España, confirmando así una tendencia a no cerrar las 
investigaciones históricas a la especificidad de un medio, sino a establecer relaciones con otras prácticas comunicativas.

Dicha tendencia está en sintonía con nuestra elección teórica, que es la que nos mueve a seleccionar fuentes que no solo comentan el programa Conozca usted España, sino también la campaña de promoción en que se encuadra.

Desde el punto de vista metodológico, usaremos el análisis del discurso (para una explicación general, ver Santander, 2011) para sintetizar vetas y genealogías ideológicas subyacentes a los diferentes textos que se van a citar, así como para detectar prácticas mediáticas y reacciones relevantes relacionadas con la campaña y la serie. Buscamos extraer los significados y connotaciones de párrafos enteros y de términos específicos ("democrático", "ochocentista", "folclore"...), que son síntomas de la renovación del discurso sobre el país.

Se van a cubrir de forma sistemática, con el apoyo de documentación del periodo: origen de la campaña y su despliegue (apartados 1.1 y 1.2), características principales de su concreción televisiva a nivel de producción y discurso (2.1, 2.2, y 2.3), y justificación de la relevancia de esta serie a tenor de los comentarios de audiencia (2.3) y crítica (3). Para seleccionar los textos, hemos acudido a las siguientes fuentes.

El programa Conozca usted España consta de cincuenta capítulos de media hora, que se emitieron en TVE entre mayo de 1966 y octubre de 1969, la mayoría centrados en una ciudad o región española mostrada por una celebridad local, aunque otros se dedicaron a mostrar prácticas como deportes invernales, moda, o incluso el funcionamiento de algunas instituciones. Tras accederlos a través del archivo ARCA de RTVE$^{5}$, hemos seleccionado los tres episodios que, a nuestro juicio, mejor revelan las contradicciones discursivas de la operación "Conozca usted España".

Tabla 1. Capítulos seleccionados de Conozca usted España. Elaboración propia

\begin{tabular}{llll} 
Capítulo & $\begin{array}{l}\text { "Entre naranjos. } \\
\text { Valencia” }\end{array}$ & $\begin{array}{l}\text { "La bahía de } \\
\text { Santander" }\end{array}$ & $\begin{array}{l}\text { "Santander, } \\
\text { ciudad de verano" }\end{array}$ \\
\hline Director & Pedro Olea & Mario Camus & $\begin{array}{l}\text { César Fernández } \\
\text { Ardavín }\end{array}$ \\
Fecha de emisión & $16-2-1967,22.15$ & $14-6-1968,23.15$ & $6-9-1968,21.50$ \\
Canal de emisión & La 1 & La 1 & La 1
\end{tabular}

\footnotetext{
${ }^{5}$ Todos los capítulos han sido visionados y están disponibles en el archivo ARCA de RTVE excepto "El toro de lidia", de Ramón Masats, emitido el 8-8-1969 (según ABC Madrid 8-8-69, p. 55 y Teleradio 4-869, p.3.) y "Ávila", del que no se ha recuperado información.
} 


\begin{tabular}{|c|c|c|c|}
\hline Presentador & José Iturbi & $\begin{array}{l}\text { José Hierro, Pancho } \\
\text { Cossío }\end{array}$ & Puri Villa \\
\hline Guion & $\begin{array}{l}\text { Pedro Olea, } \\
\text { Martín } \\
\text { Domínguez }\end{array}$ & Mario Camus & $\begin{array}{l}\text { César Fernández } \\
\text { Ardavín }\end{array}$ \\
\hline Operador & $\begin{array}{l}\text { Francisco } \\
\text { Madurga, Tomás } \\
\text { Mas }\end{array}$ & $\begin{array}{l}\text { Juan J. Baena, Juan } \\
\text { M. de la Chica, } \\
\text { Tomás Mas }\end{array}$ & $\begin{array}{l}\text { "Segis", José de la } \\
\text { Rica }\end{array}$ \\
\hline Producción & $\begin{array}{l}\text { Joaquín Sánchez } \\
\text { Ortiz }\end{array}$ & $\begin{array}{l}\text { Joaquín Sánchez } \\
\text { Ortiz }\end{array}$ & $\begin{array}{l}\text { Joaquín Sánchez } \\
\text { Ortiz }\end{array}$ \\
\hline
\end{tabular}

Fuentes: Archivo ARCA de RTVE, Hemeroteca $A B C$.

Por otra parte, para comentarios relativos a la recepción nos apoyaremos en la hemeroteca, con referencias a publicaciones generalistas (hemeroteca $A B C$ ) y especializadas (la revista editada por RTVE, Teleradio). Se han seleccionado las apariciones más polémicas de la frase "Conozca usted España" en dichos medios, en contextos heterogéneos: crítica televisiva, cartas al director, artículos de opinión...

Por último, se aportarán algunos documentos internos del MIT relacionados con la campaña, consultados en el Archivo General de la Administración.

La selección de textos se apoya además en los tres puntos de interés ya citados a propósito del marco teórico: se buscan las razones que mueven a la realización de un documental, sus dinámicas de financiación y producción, y sus particulares usos dado su contexto de distribución.

\section{El turismo interno a través de la campaña "Conozca usted España"}

Hacia mediados de los años sesenta ya era palmaria la necesidad de diversificar la actividad turística, y puede constatarse el interés de Fraga en esta cuestión (Moreno Garrido, 2007: 241). El turismo interior se perfilaba como alternativa para momentos de menor demanda foránea. Su expansión fue poco posterior al boom de visitantes extranjeros, pero su importancia se consolidó en los setenta y ochenta (Bote, Marchena y Santos, 1999: 184). 


\subsection{Origen e ideología de un eslogan}

"Conozca usted España" fue la gran campaña de promoción del turismo interno en el contexto del boom de los sesenta. $A B C$ recoge una pequeña polémica a propósito del origen del eslogan, entre el director general de Promoción del Turismo, Juan de Arespacochaga, y el periodista Luis de Castresana. Castresana escribió en ABC (Madrid, 24-6-65, p. 55-56) un artículo de opinión titulado "Conozca usted España" que comenzaba con las siguientes palabras:

Me gustaría ver carteles con este rótulo pegados en todas las esquinas. Pero no en Amsterdam o en Londres, no en Estocolmo o en París -donde ya existen por millares y han cumplido y cumplen una excelente labor-, sino aquí, entre nosotros (...) Y es un alivio comprobar como poco a poco, tras haber conquistado el turismo internacional, se intenta ahora, lo diré empleando palabras del No-Do, poner España al alcance de todos los españoles.

A lo largo del artículo, el periodista desarrolla tres argumentos que justifican su deseo:

1) Despreciar tanto el triunfalismo propagandístico como la tradición "negrolegendaria" a la hora de componer un discurso sobre España, y proponer la superación de ese supuesto dilema:

Un sentido autocrítico, inteligente y sereno puede y debe servir para no caer en el pozo del narcisismo, del "Viva España y olé". Ese mismo sentido autocrítico puede y debe servir, igualmente, para que no caigamos en el otro pozo, igualmente funesto, de la queja a diestra y siniestra y del masoquismo.

2) Vehicular esa superación a través de la mirada del turista extranjero. A través del ejemplo de la mirada de un amigo americano, Castresana sugiere que la fascinación por España no se articula mediante la superficial vía de sol y flamenco, sino mediante una suerte de análisis sociológico en el cual el catolicismo (frente al protestantismo y otros) es el garante de una espontaneidad opuesta a la modernidad:

Dicen que el extranjero viene a España porque aquí hay sol y toros y flamenco, porque la historia se extiende como un paisaje físico a la vuelta de todas las carreteras, y porque la vida es barata. Yo creo que es todo eso y es algo más que todo eso. (...) [L]o que ocurre es que Europa está poblada por ciudadanos y España está poblada por criaturas humanas. $Y$ el turista encuentra aquí una naturalidad (...), una humanidad prácticamente desaparecida o atenuada en otras latitudes.

En este punto, se puede considerar que el artículo de Castresana entronca con la propuesta realizada desde el ámbito de los estudios culturales de que, más que la banalización de una esencia nacional preexistente, el turismo ha sido una de las principales industrias de construcción y puesta en circulación de ciertas imágenes y 
discursos identitarios (Olivella y Afinoguénova, 2008: xvi), sin perjuicio de que esas imágenes beban de tradiciones iconográficas centradas en lo pintoresco (de Diego, 2011: 24) que enfatizan el carácter esencialmente premoderno del país.

3) Tener por horizonte de todo este movimiento tanto la promoción del turismo interno como, especialmente, la convivencia armónica entre españoles.

Tal vez no fuera mala cosa si todos tratáramos de conocer mejor a España y, por ahí, llegar a un mejor conocimiento de nosotros mismos. (...) Tal vez entonces acabaríamos comprendiendo de una vez para siempre (...) que, en verdad, a los españoles, a todos los españoles, son más (y más importantes) las cosas que nos unen que las cosas que nos separan.

Del análisis de este texto puede inferirse que, pese a estar escrito por un particular, resume de forma bastante completa algunas de las principales líneas ideológicas del MIT en el periodo de Manuel Fraga Iribarne: la pretensión de objetividad del desarrollismo, en forma de realismo optimista; la apertura a la influencia exterior sin renunciar a un supuesto carácter nacional de raigambre católica; y la apuesta por una reconciliación nacional en torno al progreso, tal y como habían promulgado hacía menos de un año los fastos de la campaña "XXV Años de Paz"6.

Unos meses después ( $A B C$ Madrid, 16-9-66, p. 32), Castresana advierte el uso del eslogan por parte del MIT y se pregunta si la institución se inspiró en su artículo. A tenor de ese comentario, el director general de Promoción del Turismo, Juan de Arespacochaga, aclara el origen del lema en el seno del MIT en una carta publicada en $A B C$ (Madrid, 21-9-66, p. 32):

En relación a la nota de don Luis de Castresana, publicada el 16 del corriente en $A B C$ (...) me gustaría aclarar que el Ministerio de Información y Turismo decidió utilizar la expresión "Conozca usted España" bastante antes (...). Con fecha 26 de noviembre de 1964, la Dirección General de Promoción del Turismo envió una circular a los delegados provinciales del Ministerio en la que, considerando muy importante el mutuo conocimiento entre los habitantes de las diversas provincias de España, tan variadas como bellas y atractivas, se les encomendaba una promoción específica que, bajo el "slogan" "Conozca usted España", intentara dar a conocer España a los españoles y que estos se conocieran entre sí a través de una fuerte corriente turística interior.

De modo que, a propósito de ese intercambio epistolar en las páginas del citado diario, proponemos que es posible localizar tanto la motivación y objetivos de la campaña

\footnotetext{
${ }^{6}$ Una caracterización de la campaña "XXV Años de Paz", muy significativa del periodo de Fraga al frente del MIT, puede encontrarse en Tranche y Sánchez-Biosca (2000: 421).
} 
desde un punto de vista institucional, como un explícito repaso de las líneas ideológicas en que esta se inscribe.

\subsection{El despliegue transmediático de la campaña}

Desde antes del estreno de la serie, la prensa publicó noticias de diferentes iniciativas vinculadas a la campaña. Especialmente, notas sobre exposiciones que recogían los recursos turísticos de una provincia, y que se estrenaban en su propia capital, pero podían trasladarse, a modo de gira, a otras. Como ejemplo, véase la noticia en $A B C$ (Madrid 16-4-65, p. 59) de la inauguración en el Castillo de Santa Bárbara de la muestra "Conozca usted España - Costa Blanca de Alicante", o la de la exposición inaugurada en León ( $A B C$ Madrid, 3-9-65, p. 77), que aspiraba a iniciar pronto un "peregrinaje divulgador por toda la geografía Española". Nótese que por "recurso turístico" la primera muestra entendía número de plazas hoteleras y la segunda muestras de arquitectura prerrománica.

La imagen y el audiovisual estuvieron presentes desde temprano en la campaña, 0 vinculados a ella. Así, $A B C$ (Madrid, 18-8-65, p. 35-36) recoge cómo el "Día del turista" se celebró en Cuenca con una exposición incluida en "Conozca usted España", compuesta por fotografías de gran formato centradas en el "tipismo" de la región. También con la proyección de tres documentales sobre la provincia en los cines de la ciudad, combinada con actuaciones folclóricas impregnadas de "típico sabor tradicional".

La descripción de esas actividades sirve como muestra de la fuerte influencia de conceptos pseudoetnográficos en la construcción turística de la imagen de muchas provincias, en especial las de interior. Como apunta Fuentes Vega (2017: 70) en su análisis de imágenes del boom turístico, el régimen tuvo siempre reticencias a la hora de incorporar a su iconografía muestras del primitivismo que tanto había atraído a viajeros ingleses, franceses o alemanes en los cincuenta (ahondando en una tradición que tiene sus raíces en el siglo $\mathrm{XIX)}$ por temor a proyectar una imagen de subdesarrollo, aunque concedió algo de espacio a ese deseo a través de una folclorización extrema de ciertos contextos rurales, basada en imágenes tan estilizadas y depuradas de la tradición que pueden calificarse como hiperreales.

Hay un último aspecto fundamental para comprender desde dónde se leyó la serie de televisión estrenada en el año 1966. Quizá lo más importante de "Conozca usted España" fue su iniciativa de subvención al turismo interno. Las menciones en $A B C$ son muy numerosas: se comentan las excursiones en la provincia de Sevilla ( $A B C$ Sevilla, 20-8-65, p. 35), Cáceres ( $A B C$ Madrid, 14-11-65, p. 82) o Santander ( $A B C$ Madrid, 19-466, p. 67). Esta rama de la operación debe entenderse como el comienzo de una externalización del turismo social: es decir, como un eslabón intermedio entre los 
centros vacacionales sindicales que habían sido habituales en las dos décadas anteriores, y las futuras políticas de subvenciones (IMSERSO, etc.) con las que se va a gestionar el turismo social en colaboración con empresas privadas.

A partir de la exposición de todas estas fuentes, se puede caracterizar una campaña de renovación de la imagen de España sostenida en las claves ideológicas que hemos detectado en prensa, y cuyas primeras imágenes fueron las de las citadas exposiciones de recursos turísticos, amalgamas de infraestructuras, arte y folclore. Así, podemos hablar de red multimediática en el seno de "Conozca usted España", e incluso de transmediación: las relaciones de significados entre prensa, cartelería, publicidad de empresas privadas ${ }^{7}$ y televisión contribuyeron a consolidar un imaginario turístico para los españoles. Siguiendo con la definición de Medienverbund, vamos a ver cómo puede argumentarse que existieron también elementos de conexión entre medios a propósito de ciertas prácticas mediáticas.

\section{Caracterización de la operación "Conozca usted España"}

Conozca usted España se estrenó como serie de televisión el viernes 6 de mayo de 1966 a las 23.00 horas en el primer canal de TVE. Se emitieron nuevos capítulos en este canal hasta 1969; también fue regularmente repuesto. Entre 1968 y 1969, algunos capítulos se estrenaron en la segunda cadena. Como recoge Palacio (2008: 70), las encuestas disponibles atribuyen al programa una audiencia media de 4.265.000 espectadores.

Las menciones a la serie Conozca usted España en la historiografía televisiva recalcan que en su génesis se hallan un empeño personal de Manuel Fraga y un espíritu de renovación asociado a la recién inaugurada segunda cadena de TVE (Fernández, 2014: 56), especialmente porque Salvador Pons era el coordinador del programa y a la vez alto responsable del nuevo canal.

\footnotetext{
${ }^{7}$ En $A B C$ Madrid (23-4-66, p. 77) aparece un anuncio de Viajes Marthe S.A. en el que la empresa se apoya sobre la campaña de promoción institucional: al presentar su oferta para un viaje a Palma, subraya "Es una gentileza de Viajes Marthe S.A. colaborando así en la campaña de televisión de "Conozca usted España"”. Esa conexión público-privada da idea de que la campaña no fue solo un proceso de comunicación unidireccional arriba-abajo desde el MIT, sino que el lema se instaló en el imaginario colectivo a través de una red más compleja de emisores.
} 
Pocos meses después de ese estreno, un documento interno del MIT dirigido a Fraga recogió una propuesta que buscaba identificarse con el mismo eslogan (los destacados son nuestros) $)^{8}$ :

Nota para el Excelentísimo sr. Ministro. 2-7-66.

(...) [S]e ha acordado:

Conveniencia de realizar un documental bajo el título "Conozca usted España” (...)

(...) [I]nteresa contar con una filmoteca en la que se cubran los temas concretos que piden los agentes de viaje y las entidades que trabajan en contacto con nuestras Oficinas en el extranjero. El mejor sistema de formar esta filmoteca de temas locales, se acuerda, es el de animar a las productoras de cortos a realizar documentales cinematográficos que cubran estos temas prometiéndoles, no naturalmente la financiación del documental, sino el adquirirles un determinado número de copias si el film resulta bueno para los fines publicitarios de la Subsecretaría de Turismo. La mejor garantía de que el film resulte bueno es la de la personalidad del Director que propongan para el documental y del guion.

Argumentamos que los tres subrayados se pueden relacionar con tres prácticas que caracterizaron la producción mediática del MIT en la operación de renovación de imagen del país:

1) La "personalidad del Director", con mayúsculas: el prestigio autoral como primera garantía de calidad es representativo de algunas de las teorías en boga entonces en el mundo del audiovisual.

2) La referencia a "animar a las productoras", pero "naturalmente" sin financiarlas, es elocuente respecto al sistema de producción que alentó el MIT, siempre externalizado, si bien a partir de finales de los años sesenta focalizó esa externalización en el NO-DO, como apunta Matud Juristo (2007: 405).

3) La mención a "los temas concretos que piden las agencias de viajes" remite a una influencia de la mirada del turista extranjero.

Argumentaremos que se trata de tres prácticas que caracterizan a la red de medios auspiciada desde el MIT, ya que las encontramos en este documento, referido a proyectos cinematográficos, pero las podemos detectar también en torno a la serie de televisión Conozca usted España.

\footnotetext{
${ }^{8}$ Puede localizarse en: Archivo General de la Administración. Signatura 049.11 42405, Topográfico 23/66.603-69.301.
} 


\subsection{Importancia de la autoría}

La serie Conozca usted España incorporó a varios realizadores asociados a la Escuela Oficial de Cinematografía (Mario Camus, Pedro Olea, José Luis Borau, Claudio Guerin...). José María García Escudero, director general de Cinematografía durante la mayor parte del periodo de Fraga en el MIT, había mostrado un gran interés por promocionar la carrera de esa generación de cineastas cuya producción de la década terminaría etiquetada como Nuevo Cine Español, con el objetivo fundamental de renovar en el exterior la imagen de España y su cine $e^{9}$. Sin embargo, a menudo estos directores se enfrentaban a dificultades económicas para sacar adelante sus películas, que llevaron a varios de ellos a realizar trabajos para televisión desde mediados de los sesenta.

Hay que tener en cuenta que probablemente la distribución que más interesaba al régimen en el caso del Nuevo Cine Español era el circuito internacional de festivales de cine de primera categoría, como recogen varios capítulos de la compilación sobre los "nuevos cines" en España de Carlos F. Heredero y José Enrique Monterde (2003). Sin embargo, una serie en prime time en un contexto de monopolio televisivo buscaba sobre todo la atención de los españoles, aunque eso no fuera obstáculo para que, igual que otros programas de prestigio como Historias de la frivolidad (1967) o La cabina (1972), algunos capítulos de Conozca usted España acudieran a festivales internacionales de televisión. Por ejemplo, el capítulo "La ría de Bilbao", de Pedro Olea, que representó a España en el Festival de Praga de 1967, como se reseña en $A B C$ Madrid (18-6-67, p. 105).

En parte por influencia de la crítica francesa, la noción de autoría era, en el audiovisual de los sesenta, un marchamo internacional de calidad y un principio teórico que consagraba la libertad (relativa) del director, aunque esa autonomía no evitara en España conflictos con la censura (véase la entrevista realizada por Hernández (2003) a Miguel Picazo). No es sorprendente que estuviera en la base de la apuesta institucional por los egresados de la E.O.C.; quizá sí lo es algo más que se aplicara igualmente a la televisión y a la promoción turística, con un mismo objetivo renovador. Así lo confirman las palabras del coordinador Salvador Pons, quien afirmó, en declaraciones recogidas en Teleradio (16-5-66, p. 11-12), que el programa buscaba la heterogeneidad y la mirada autónoma de los jóvenes directores, "para que la visión resulte nueva y para que tengan la posibilidad de moverse en un campo, como la televisión, abierto a todos y tan interesante para ellos". Además, es destacable que en numerosas ocasiones se ofreciera a los directores la posibilidad de dirigir un episodio sobre su ciudad de origen.

\footnotetext{
${ }^{9}$ La referencia a la promoción institucional del Nuevo Cine Español se puede encontrar en la abundante historiografía cinematografía del periodo: Torreiro (2009), Zunzunegui (2005)...
} 
Un ejemplo de capítulos con vocación autoral son los de Mario Camus, notablemente novedosos en lo formal, como "La bahía de Santander". En este, emitido por primera vez el 14 de junio de 1968 (según $A B C$ Madrid, 14-6-68, p. 134), un moderno uso de los movimientos de cámara (travellings, zooms...) se combinaba con un retrato melancólico de diferentes huellas del pasado de la ciudad. La preferencia por esa atmósfera decadente entronca con algo del espíritu de títulos de esa década del director santanderino, como Young Sánchez (1963) o Con el viento solano (1966).

\subsection{Externalización de la producción}

A diferencia de otros ministerios, donde la producción oficial de documentales estaba estrechamente vinculada a una persona más o menos relacionada con la institución ${ }^{10}$, en el MIT fue habitual la práctica descrita en el documento ya citado: una combinación de subvenciones y adquisiciones de filmes para que las productoras privadas realizaran las películas que más convenían. Quizá la razón de ser de esta práctica esté asociada con la aparente inespecificidad de las temáticas requeridas por un departamento de Turismo, a diferencia de la consideración que merecían documentales de tema industrial o agrícola.

Existe cierto parentesco entre esa forma de trabajar y el modelo de producción que se instaló en estos años en TVE, del cual precisamente fue pionera la serie Conozca usted España, según Palacio (2000: 33). Este consistía en: la organización en torno a un coordinador en lugar de un productor (Pons, en este caso); el encargo de cada capítulo a un director específico, por motivos concretos; la autonomía de este para trabajar y para elegir a su equipo, con una revisión censora aplicada únicamente con el episodio acabado.

Determinados hitos de audacia de la serie tuvieron que ver con esa política de hechos consumados. Por ejemplo, los que encontramos en el capítulo "Entre naranjos", de Pedro Olea, emitido por primera vez el 16 de febrero de 1967 según la programación de $A B C$ (Madrid, 16-2-67).

En él, se cuela una doblemente interesante reivindicación lingüística: un explícito plano de una pintada que reza "Parlem valencià" en el valenciano Puente de Serranos, y un cierre con la canción "Al vent", sentida por algunos televidentes como la primera aparición de la música de Raimon en TVE ${ }^{11}$. Según Fernández Penas (2015), la inclusión

\footnotetext{
${ }^{10}$ Como el Marqués de Villa-Alcázar en Agricultura, o Luis Suárez de Lezo en el INI (España. Comisión Interministerial de Documentales Cinematográficos Oficiales, 1964).

${ }^{11}$ Encontramos el siguiente testimonio en las cartas al director de Blanco y Negro (27-5-67, p. 7): “(...) Tenemos otro cantante, Raimon, que al igual que Serrat compone sus propias canciones, al que aún no se ha visto en TV. (Lo único que a través de las pantallas le hemos oído fue su bellísima canción "Al vent", con música de fondo a un programa de la serie "Conozca usted España"). Una no se cansaría de
} 
de esta canción puede entenderse como el límite de lo tolerable en televisión, pues motivó una llamada de Fraga a Salvador Pons que provocó que Olea no dirigiera más capítulos.

Por otra parte, también aparece una referencia al valenciano Tribunal de las Aguas en la que la voz en off, sin desbordar absolutamente los límites de la entonces muy en boga idea de democracia orgánica, puede ser leída desde la ambigüedad cuando afirma: "la riqueza la creó sobre todo ese sentido colectivista y democrático del agua que sitúa a todos en un pie de igualdad ante la ley no escrita. Lo mismo al poderoso señor como al más humilde regante. Esto es mucho más que simple folclore".

\subsection{Identificación con la mirada turística}

El imaginario turístico frecuentemente se ha puesto en relación con aspectos identitarios nacionales. En el caso de España, a menudo la cuestión se ha planteado desde los estudios culturales, con la pregunta: ¿cómo ha afectado la mirada del extranjero a la percepción que tienen los españoles de sí mismos, desde que el turismo moderno dio sus primeros pasos con los viajeros románticos del siglo XIX?

En muchos de estos trabajos resuenan de fondo los ecos de textos seminales sobre el turismo que plantearon esta actividad en términos de mercantilización de culturas (Turner y Ash, 1991), de construcción de espacios hiperreales (Augé, 1998) o de juego de expectativas entre postal y mirada (Urry, 1990). Si bien la idea de "autenticidad" que subyace a algunos de aquellos escritos resulta hoy poco operativa en términos teóricos, las dinámicas coloniales sugeridas en ellos han sido susceptibles de matizarse y explorarse más, tanto en debates históricos como aplicadas al presente. Desde el punto de vista discursivo, esto ha conducido a la hipótesis de que España "constituye un caso particularmente interesante de auto-identificación nacional como destino para un Otro, siempre más moderno" (Afinoguénova, 2007: 38).

La recepción del programa Conozca usted España se puede considerar un espacio de negociación de esa supuesta "auto-identificación", que permite vislumbrar que quizá nunca hubo un consenso real de los españoles en torno a ciertos símbolos de armonía entre tradición y modernidad, ni una identificación generalizada con el discurso official, como a veces sugieren los estudios sobre el tema.

Un ejemplo muy interesante en este sentido es la representación de la ciudad de Santander en la serie. El ya citado capítulo de Camus recogía desde la rebeldía de los antiguos cántabros frente a los romanos, al incendio de 1941, pasando por varias 
referencias al siglo XIX como la conexión marítima con Cuba. Veamos la protesta de un televidente al respecto, aparecida en las cartas al director de Blanco y Negro (6-7-68, p. 3-4):

Ciertamente, no acertamos a comprender qué es lo que T.V.E. pretendía darnos a conocer con tal filmación. Si su interés radicaba en presentarnos una ciudad ochocentista, vetusta y sin vida, creemos que lo logró con creces, puesto que lo único que nos mostró a placer, fue un caserío viejo y a media altura, suspendido en el aire sin que se alcanzasen a ver las calles en que se asentaban, en el que no faltó la clásica nota de la ropa tendida, no digamos que al sol, puesto que el gris de un otoño rozando a invierno, fue la nota característica del colorido. (...)

Se ha dicho que Santander es el Ave Fénix que ha surgido de sus cenizas con mayor fuerza y pujanza; ¿por qué, pues, no se demostró? ¿Acaso Santander y su bahía no tienen una belleza natural extraordinaria en exuberancia y verdor? (...) ¿Es que acaso no son dignos de enseñarse al mundo entero los jardines Piquio, orgullo de la Montaña, y las playas de la Magdalena, Mogro y Pedreña (...)? ¿Y los paseos de Calvo Sotelo, Reina Victoria y Pereda, con sus modernos y fantásticos edificios?

Sánchez-Biosca (2000: 464-465) recuerda la preferencia del franquismo por rememorar el periodo imperial, en especial el reinado de Felipe II, y su aversión al siglo XIX, presentado como decadente e inestable. Desde esa influencia debe entenderse, quizá, la crítica al ochocentismo; sin embargo, proponemos que la necesidad de mostrar las playas, el sol y la modernidad para dar una imagen adecuada, puede concebirse como una identificación del espectador con la propaganda turística, a menudo influida por la mirada extranjera ${ }^{12}$.

Hay que destacar que la opinión de este televidente debió de ser lo bastante compartida por los responsables de la serie como para que, poco después, se emitiera otro capítulo titulado "Santander, ciudad de verano", dirigido por César Fernández Ardavín y emitido el 6 de septiembre de 1968.

Como indica el título, este capítulo se centró en aspectos puramente vacacionales; y en cuanto a la forma, es casi el único capítulo de toda la serie Conozca usted España en el que el hilo conductor (la presentación de Puri Villa) se organiza abiertamente en forma de ficción, con una voz en off de estructura epistolar dirigida a una amiga inglesa que incorpora numerosos fetiches de la mirada turística (por ejemplo: "Querida

\footnotetext{
12 Pueden consultarse al respecto numerosas cartas en las que televidentes reclaman que las ciudades muestren en la serie una cara más agradable, atractiva para el visitante y acorde con sus expectativas, incluyendo todos los monumentos que el turista ya conoce: respecto a Melilla (Teleradio, 31-7-67, p. 4), a Barcelona ( $A B C$ Sevilla, 11-5-66, p. 61).
} 
Margaret: acabo de llegar y aún tengo en los ojos metida la imagen de mi ciudad vista desde el aire").

Sin embargo, también es digno de mención que hubiera un espectador santanderino que salió en defensa del capítulo de Camus, asegurando que su mérito es precisamente huir de "la postal", cuyo testimonio extraemos de las cartas al director de Blanco y Negro (27-7-68, p. 3):

Y el mérito para mí de este Santander (...) se debe a haberse sabido salir del patrón del Santander postal, archiconocido y muy adivinado, y presentar el íntimo: el Santander de los santanderinos (...).

A mi entender, las estampas del Santander antiguo y sus eruditos comentarios, que son su "gran complemento", me han hecho conocer no su ochocentismo (...), sino los principios comerciales de una ciudad (...).

La fotografía en blanco y negro, más bien un gris admirablemente conseguido, es el Santander de la mayoría de los días del año, y por añadidura de cualquier puerto del Cantábrico, y Televisión Española aún no exhibe en sus pantallas el tecnicolor, para los exuberantes verdores de la montaña que usted añora. (...)

Así, si hablamos de negociación de significados en el seno de la recepción de esta serie es porque la citada auto-identificación con la postal de sol y playa no es total, ni forzosamente mayoritaria, como puede verse en la anterior carta. Después de todo, pese a su mutua interconexión, ni los imaginarios ni los intereses de visitantes y locales se identificaron nunca de forma completa.

Como sabían en el $\mathrm{MIT}^{13}$, dentro del país eran clave en aquel momento las tensiones identitarias nacionalistas y regionalistas, por lo que es importante que los realizadores y la audiencia se prestaran a este tipo de negociaciones acerca de la imagen de algunas demarcaciones. Consideramos que este punto (la negociación sobre la imagen de las regiones) es el que hilvana las tres características desarrolladas en este apartado 2.

$Y$ es que ya no era efectiva la visión del NO-DO de las tradiciones locales, que caracteriza Sánchez-Biosca afirmando que en el noticiario "se ilumina la relación que el franquismo postulaba o suponía entre lo singular de cada región y lo general del espíritu español, el sentido del folclore y las costumbres de cualquier pueblecito en cuanto representación sinecdóquica de esa España que concebía como una e indivisible" (2000: 530).

\footnotetext{
${ }^{13}$ Por ejemplo, ya en 1964 Fraga visitó la Feria de San Jorge de Barcelona y afirmó en su discurso: “(...) la unidad de la Patria no se ve, no puede verse amenazada, por el cultivo del idioma vernáculo (...). Este constituye un acusado matiz específico de nuestro ser nacional que contiene elementos ciertos de una cultura propia cuya unión a los que recibe del resto de España enriquece a ésta y contribuye a formar nuestra variada y sólida personalidad" (La Vanguardia, 24-4-1964, p. 5).
} 
Muy al contrario, en esta nueva época, para transmitir una imagen de "autenticidad", esencialista pero a la vez actualizada, encarnada en lo regional ${ }^{14}$, se confió en la mirada original de los realizadores (mirada incluso emic, en el caso de los autores oriundos de las ciudades que mostraban), se ensancharon los límites de lo reivindicable gracias al nuevo modelo de producción (recordemos el Tribunal de las Aguas, definido como "mucho más que simple folclore", superando así las propuestas de las exposiciones citadas en el apartado 1.2), e incluso se lanzaron mensajes tan contradictorios como los de los capítulos de Camus y Ardavín.

\section{Estandarización de las novedades introducidas en el medio televisivo}

Además de las ya explicadas redes de medios y de prácticas mediáticas, existe un último argumento para detectar que, en muchos sentidos, las aportaciones a la historia de la televisión de la serie Conozca usted España entroncan con aspectos que van más allá de la especificidad del medio, y que justifican la relevancia y representatividad del programa escogido. Precisamente, se trata de su contribución al debate sobre esta misma especificidad de la televisión.

La recepción de la serie por parte de la crítica fue, en general, muy favorable al esfuerzo de producción propia de TVE, leído por la crítica como intento de "españolizar" la parrilla ( $A B C$ Madrid, 10-8-79, p. 62). Un único factor levantó las dudas, de, por ejemplo, el crítico de $A B C$ Enrique del Corral: la noción de "televisualidad". Muchos de sus textos resaltaban la suficiente o insuficiente cualidad televisiva de cada capítulo, empezando por la reseña del primero ("Las Ramblas", de Ramón Masats), titulada elocuentemente "Esto no es televisión" (ABC Madrid, 8-5-66, p. 109). En ella, del Corral puntualiza: "Es una serie de documentales cinematográficos "que se pasan" en televisión. Que no es lo mismo". Si atendemos a este y otros artículos $^{15}$ del mismo autor, entendemos que en su opinión la televisión debía ser:

- Más auténtica que autoral, frente al cine, que puede incorporar más marcas de autor, un uso lírico de la imagen-tiempo, etc.

\footnotetext{
${ }^{14}$ Para un mayor desarrollo del papel de los regionalismos en el nacionalismo español, puede verse la genealogía de Archilés (2006) en "«Hacer región es hacer patria». La región en el imaginario de la nación española de la Restauración".

${ }^{15}$ Por ejemplo, las reseñas de los capítulos "La casa de Alba" (ABC Madrid, 16-6-66, p. 119), "Canto a la Andalucía musulmana" (ABC Madrid, 16-10-66, p. 118) o "El principado de Asturias" (ABC Madrid, 30-1066, p. 117).
} 
- Sencilla, humana, no grandilocuente, frente al cine, que puede ser más ambicioso.

- Creadora de un texto subordinado a la recepción, frente al cine, que crea un texto más independiente que requiere un espectador activo.

Además, había que utilizar para todo ello recursos estilísticos concretos, como por ejemplo los primeros planos, pensados para la pequeña pantalla. Hay que señalar, por tanto, que el impulso renovador que supuso Conozca usted España en TVE trascendió algunas convenciones sobre el medio vigentes entonces, si bien no del todo consolidadas debido a la corta andadura de la televisión española.

Lo interesante es que, de algún modo, esas novedades se convirtieron en canon. Así lo podemos ver al explorar menciones posteriores a la serie en diferentes contextos.

En primer lugar, como forma de explicar en qué consisten otros programas, lo cual indica que Conozca usted España fue durante algún tiempo una especie de estándar. Por ejemplo, Enrique del Corral firma una crítica de la serie Algo más que un nombre (1967-1968) en ABC Madrid (11-2-68, p. 97): "Es como un gran reportaje de una ciudad a lo "Conozca usted España", solo que hecho con menos pretensiones". O bien, encontramos en Teleradio (27-3-67, p. 37) un artículo a propósito de Fiesta (19661968): "es un programa similar a "Conozca usted España" que, en lugar de veintisiete minutos de duración, tiene cincuenta y cinco, y en vez de ocuparse de toda una provincia o una ruta turística lo hace de una pequeña localidad (...)". Incluso en fecha tan tardía como 1977, encontramos que del Corral escribe en ABC Madrid (16-3-77, p. 118):

"Conozca usted España" fue un inolvidable programa de TVE 2 nacido de la mente de Salvador Pons, si no recuerdo mal. Programa en el que hicieron vela de armas directores y documentalistas cualificados dando seriedad y contenido a televisión. Bien; como destello feliz de aquel espacio, "Reportaje" emitió el lunes "España incógnita", de Manuel Miner Otamendi, con "Los maragatos".

En segundo lugar, hay que destacar el interés que tiene la serie en la fijación de un canon en la España de su tiempo respecto a qué es un documental. El uso equivalente de los términos "cortometraje" y "documental" había sido frecuente hasta los años sesenta. Conozca usted España fue un programa pionero en ese contexto de resurgimiento del interés por la naturaleza del documental, como puede detectarse en un artículo muy posterior, aparecido en Teleradio (1-7-91, p. 7):

La exhibición obligatoria del NO-DO en nuestras salas cinematográficas hizo que la producción de cortometrajes se redujera al mínimo, limitándose casi al desaparecido "Imágenes". Esto hizo que no aparecieran grandes documentalistas y que no se cultivara distinguidamente el género. TVE produjo series, no muy 
numerosas, pero sí de gran interés. "Conozca usted España", que se emitía en TVE-1, es la primera serie de documentales (...) es "la teoría del documental".

En resumen, si a su estreno surgieron dudas sobre si Conozca usted España era un producto completamente adecuado para televisión, estas se disiparon con el tiempo: impuso su estilo en TVE durante los años siguientes, en que surgieron otras series documentales que no temían rodar grandes planos generales en exteriores, permitirse destellos marcadamente autorales o ser relativamente exigentes con el espectador ${ }^{16}$.

\section{Conclusiones}

Conozca usted España fue un programa importante en la evolución de la producción propia de TVE: introdujo en television la mirada autoral de una nueva generación, sirvió como modelo de una particular estructura de producción, puso en pantalla representaciones que trascendían el tópico... Como se ha probado en el apartado 3, la serie cuestionó el concepto entonces vigente de "televisualidad", y permaneció durante años como estándar no solo de documental geográfico, sino de documental en general.

Esas novedades deben entenderse en un contexto de construcción de una nueva imagen de España, que circulaba a través de diferentes medios: desde el auge del Nuevo Cine Español hasta las exposiciones de recursos turísticos. Es posible argumentar que la televisión fue una pieza clave en la articulación de esa renovación, sobre todo a nivel interno, pero es relevante cómo unos medios se apoyaron en otros. Como se ha visto en el apartado 2, hay correspondencias entre cine y televisión respecto a nuevas ideas y prácticas como autoría, externalización...

Los trasvases transmediáticos de significados giraron en torno a una serie de líneas ideológicas, cuya génesis se puede rastrear hasta la campaña "XXV Años de Paz". Hablamos, por tanto, de líneas estrechamente ligadas al MIT de Fraga. Sin embargo, señalar la agencia del ministerio no implica que no se dieran procesos de negociación en torno a esta nueva imagen del país. Uno de los más destacados es la aceptación parcial y selectiva de la mirada del turista.

Así, el concepto de primitivismo que tanto atraía a los extranjeros es rechazado tanto por la audiencia española como por el gobierno, pero la aceptación del país soleado, alegre $\mathrm{y}$ en desarrollo generará tensiones; valgan como ejemplo las diferentes

\footnotetext{
${ }^{16}$ Además de las ya citadas Fiesta o Algo más que un nombre, se pueden inscribir en esta veta producciones como La víspera de nuestro tiempo (1967-1969), Si las piedras hablaran (1972-1973), Los ríos (1974-1975).
} 
percepciones de Santander analizadas en el apartado 2.3. Esta conclusión puede servir para matizar las aseveraciones de autores que han analizado el imaginario turístico desde los estudios culturales, cuando afirman que "by peddling Spain as "different", the government locked the country into the identity of a historical theme park, an island of imaginary difference"17 (Afinoguénova y Olivella, 2008: xii).

En el centro de esas tensiones se encuentra la cuestión territorial, puesto que muy a menudo la idea del extranjero de lo "pintoresco" tenía para el público español marcadas connotaciones regionales. La solución adoptada por el regimen fue estilizar y depurar la tradición a su conveniencia, pero también se abrió la puerta tímidamente a algunos autores para los que esa puesta en valor de la diversidad tenía tintes politicos, como hemos podido apreciar respecto a los trabajos de Olea en el apartado 2.2. Así, el desarrollo de un discurso renovador funcional al régimen, catalizado en parte por la mirada del turista, pasó por ofrecer una imagen de la variedad de España en la que la folclorización de las diferencias regionales convivía y se relacionaba con concepciones de la diversidad puntualmente menos estrechas.

\section{Referencias bibliográficas}

AFINOGUÉNOVA, E. (2007): "El discurso del turismo y la configuración de una identidad nacional para España", en DEL REY-REGUILLO, A. (editora), Cine, imaginario y turismo: Estrategias de seducción, Valencia, Tirant lo Blanch pp. 3363.

AFINOGUÉNOVA, E. y MARTÍ OLIVELLA, J. (editores) (2008): Spain is (still) different: Tourism and discourse in spanish identity, Lanham, Lexington Books.

ANTONA JIMÉNEZ, T. (2016): “La programación televisiva del tardofranquismo: La propaganda en las emisiones de entretenimiento y divulgación", en Revista Comunicación y Medios, no 34, Universidad de Chile. Disponible en Internet (202-2021): 10.5354/0719-1529.2016.41633

ARCHILÉS, F. (2006): “"Hacer región es hacer patria». La región en el imaginario de la nación española de la Restauración", en Ayer, no 64 (4), Asociación de Historia Contemporánea, pp. 121-147. Disponible en Internet (20-2-2021): https://revistaayer.com/sites/default/files/articulos/64-5ayer64 ConstruccionldentidadRegionalEuropaEspana NunezSeixas.pdf

\footnotetext{
17 “Vendiendo España como "diferente", el gobierno encerró al país en la identidad de un parque temático, una isla de diferencia imaginada" (nuestra traducción).
} 
AUGÉ, M. (1998): El viaje imposible: El turismo y sus imágenes, Barcelona, Gedisa.

BOTE GÓMEZ, V.; MARCHENA GÓMEZ, M.; SANTOS PAVÓN, E. (1999): “La descentralización autonómica y la diversificación de la estrategia de desarrollo turístico (1974-1998)", en PELLEJERO, C. (director): Historia de la economía del turismo en España, Madrid, Civitas pp. 135-193.

BUSTAMANTE, E. (2013): Historia de la radio y la televisión en España: Una asignatura pendiente de la democracia, Barcelona, Gedisa.

CAMPORESI, V. (1999): "Imágenes de la televisión en el cine español de los sesenta. Fragmentos de una historia de la representación", en Archivos de la Filmoteca, no 32, Instituto Valenciano de Cinematografía, pp. 148-163.

CANÓS CERDÁ, E. Y MARTÍNEZ SÁEZ, J. (2016): “La ficción seriada de TVE entre 1956 y 1989", en Index comunicación: Revista científica en el ámbito de la Comunicación Aplicada, no 6(2), Universidad Rey Juan Carlos, pp. 191-214. Disponible en Internet

(22-2-2021): https://journals.sfu.ca/indexcomunicacion/index.php/indexcomunicacion/article Lview/234

DE DIEGO OTERO, E. (2011): "Postales de España", en Quintana: revista de estudios do Departamento de Historia da Arte, no 10, Universidad de Santiago de Compostela, pp. 13-27. Disponible en Internet (25-2-2020): https://doi.org/10.15304/qui.10.657

ELSAESSER, T. (2009): "Archives and Archaeologies. The Place of Non-Fiction Film in Contemporary Media", en HEDIGER, V.; VONDERAU, P. (directores): Films that work: industrial film and the productivity of media, Amsterdam, University Press, pp. 19-34.

España. Comisión Interministerial de Documentales Cinematográficos Oficiales (1964): Catálogo de documentales cinematográficos: Producidos o adquiridos por Organismos Oficiales del Estado Español, Madrid, Dirección General de Cinematografía y Teatro.

FERNÁNDEZ, L. M. (2014): Escritores y televisión durante el Franquismo (1956-1975), Salamanca, Universidad de Salamanca.

FERNÁNDEZ PENAS, M. (2015): “La legitimación de la dictadura franquista a través de la divulgación de contenidos geográficos. Ejemplos de la serie documental Conozca usted España y del filme Días de viejo color" en Revista Cine Documental, № 12. Disponible en Internet (15-2-2021): http://revista.cinedocumental.com.ar/la-legitimacion-de-la-dictadura-franquista- 
a-traves-de-la-divulgacion-de-contenidos-geograficos-ejemplos-de-la-seriedocumental-conozca-usted-espana-y-del-filme-dias-de-viejo-color/

FUENTES VeGA, A. (2017): Bienvenido, Mr. Turismo: Cultura visual del "boom" en España, Madrid, Cátedra.

HEREDERO, C. F.; MONTERDE, J. E.; ALQUÉZAR I ALIANA, J. (editores) (2003): Los "nuevos cines" en España: llusiones y desencantos de los años sesenta, Valencia, Institut Valencià de Cinematografia Ricardo Muñoz Suay.

HERNÁNDEZ, J. (2003): "El reverso de la España idealizada. Entrevista con Miguel Picazo", en HEREDERO, C. F.; MONTERDE, J. E.; ALQUÉZAR I ALIANA, J. (editores): Los "nuevos cines" en España: llusiones y desencantos de los años sesenta, Valencia, Institut Valencià de Cinematografia Ricardo Muñoz Suay.

IBÁÑEZ FERNÁNDEZ, J. C. (2017): Cine, televisión y cambio social en España, Madrid, Editorial Síntesis.

JENKINS, H. (2008): Convergence culture: La cultura de la convergencia de los medios de comunicación, Barcelona, Paidós.

MARTÍN QUEVEDO, J. Y FERNÁNDEZ RAMÍREZ, L. (2020): “Una propuesta metodológica para el análisis histórico de la programación en televisión. El ejemplo de la Segunda Cadena de TVE (1966-1975)", en Revista Espacios, Vol. 41, № 12, Caracas, pp. 4-13. Disponible en Internet (26-2-2020): http://revistaespacios.com/a20v41n12/20411204.html

MATUD JURISTO, A. (2007): El cine documental de NO-DO, Tesis, Universidad Complutense de Madrid.

MORENO GARRIDO, A. (2007): Historia del turismo en España en el siglo XX, Madrid, Síntesis.

PALACIO, M. (2008): Historia de la televisión en España, Barcelona, Gedisa.

- (2000): “Ramón Masats y la televisión”, en CERDÁN, J. (director): Ramon Masats: Iberia inèdita, Barcelona, La Fàbrica de Cinema Alternatiu, pp. 30-40.

RUEDA LAFFOND, J. C. (2018): "La televisión, símbolo del desarrollismo franquista: Algunas claves de interpretación", en Cercles. Revista d'Història Cultural, № 21. Disponible en Internet (25-2-2021): https://doi.org/10.1344/cercles2018.21.1004 - (2014): "Franquismo banal. España como relato televisivo (1966-1975)", en ARCHILÉS I CARDONA, F. Y SAZ, I. (coordinadores): Naciones y estado: la cuestión española, Valencia, Universidad de Valencia, pp. 225-244. 
SÁNCHEZ-BIOSCA, V. (2007): "Las culturas del tardofranquismo", en Ayer, no 68, Asociación de Historia Contemporánea, pp. 89-110. Disponible en Internet (20-22021): $\quad$ https://revistaayer.com/sites/default/files/articulos/68-4ayer68 CrisisDescomposicionFranquismo Sanz.pdf

SANTANDER, P. (2011): "Por qué y cómo hacer análisis del discurso", en Cinta de Moebio, no 41, Universidad de Chile. Disponible en Internet (15-2-2021): https://scielo.conicyt.cl/scielo.php?pid=S0717554X2011000200006\&script=sci_arttext\&tlng=n

TORREIRO, M. (2009): “¿Una dictadura liberal? (1962-1969)”, en GUBERN, R. (director): Historia del cine español, Madrid, Cátedra, pp. 295-340.

TRANCHE, R. Y SÁNCHEZ-BIOSCA, V. (2000): NO-DO: El tiempo y la memoria, Madrid, Cátedra.

TURNER, L. A. Y ASH, J. (1991): La horda dorada: El turismo internacional y la periferia del placer, Madrid, Endymion.

URRY, J. (1990): The Tourist Gaze: Leisure and Travel in Contemporary Societies, Londres, Sage.

VONDERAU, P. (2009): "Touring as a Cultural Technique. Visitor Films and Autostadt Wolfsburg", en HEDIGER, V. Y VONDERAU, P. (directores): Films that work: industrial film and the productivity of media, Amsterdam, University Press, pp. 153-166.

ZAHEDI, F. (2014): "La programación de cine en TVE en la "Primavera de Aperturismo" (enero-junio 1974)", en Estudios sobre el mensaje periodístico, no 20 (especial), pp. 243-265. Disponible en Internet (26-2-2021): https://doi.org/10.5209/rev ESMP.2014.v20.45101

ZUNZUNEGUI, S. (2005): “Llegar a más. El cine español entre 1962 y 1971”, en CASTRO DE PAZ, J.L.; PÉREZ PERUCHA, J.; ZUNZUNEGUI, S. (directores): La nueva memoria: Historia(s) del cine español (1939-2000), A Coruña, Vía Láctea, pp. 130177.

\section{AUDIOVISUALES}

CAMUS, M. (1968): "La bahía de Santander" [Capítulo de serie de televisión], en PONS, S., Conozca usted España, TVE.

FERNÁNDEZ ARDAVÍN, C. (1968): "Santander, ciudad de verano" [Capítulo de serie de televisión], en PONS, S., Conozca usted España, TVE. 
OLEA, P. (1967). "Entre naranjos" [Capítulo de serie de televisión], en PONS, S., Conozca usted España, TVE. 